Çukurova Üniversitesi Mühendislik Mimarlık Fakültesi Dergisi, 34(3), ss. 255-259, Eylül 2019

Çukurova University Journal of the Faculty of Engineering and Architecture, 34(3), pp. 255-259, September 2019

\title{
Metal İçerikli Örme Kumaşların Mukavemet ve Uzama Özelliklerinin İncelenmesi
}

\author{
İlkan ÖZKAN"1 \\ ${ }^{1}$ Çukurova Üniversitesi, Mühendislik Fakültesi, Tekstil Mühendisliği Bölümü, Adana
}

Geliş tarihi: 24.07.2019_Kabul tarihi: 30.09.2019

$\ddot{\mathbf{O} z}$

$\mathrm{Bu}$ çalışmada, metal içerikli örme kumaşların eksenel gerilmeler karşısındaki mukavemet ve uzama davranışları araştırılmıştır. Çalışma kapsamında çelik, bakır ve gümüş teller eş karıştırma tekniği ile 2 adet poliamid 6.6 filament ile birleştirilerek metal içerikli iplikler üretilmiştir. Üretilen iplikler kullanılarak 1x1 Rib dokusunda örme kumaşlar üretilmiştir. Karşlaştırma amacıyla \%100 poliamid örme kumaşlar da üretilmiștir. Üretilen kumaşların sıra ve çubuk doğrultusundaki kopma mukavemeti ve uzama özellikleri TS EN ISO 13934-1 standardına göre test edilmiş ve elde edilen sonuçlar istatistiksel olarak değerlendirilmiştir. Sonuç olarak metal içerikli kumaşlar ile kontrol kumaşının mukavemet değerleri arasında anlamlı bir fark yoktur. Kumaşların çubuk yönündeki uzamalarında ise anlamlı farklılıklar tespit edilmiştir.

Anahtar Kelimeler: Metal içerikli iplik, Kopma mukavemeti, Kopma uzaması, Örme Kumaş, 1x1 Rib

\section{Investigation of Strength and Elongation Properties of Metal Containing Knitted Fabrics}

\begin{abstract}
In this study, breaking strength and elongation behavior of the knitted fabrics including metal wire under axial forces were investigated. For this aim, Stainless steel, copper and silver wires were commingled with two polyamide 6.6 filament yarns. Produced yarns were knitted to $1 \times 1$ Rib fabrics. $100 \%$ polyamide knitted fabrics were also produced for comparison. Breaking strength and elongation properties of samples were tested at course and wale directions according to TS EN ISO 13934-1 standard. Obtained results were examined statistically. According to the results, there is no significant difference between the strength values of fabrics containing metal wires and control samples. Significant differences were observed in the elongation of the fabrics in the course direction.
\end{abstract}

Keywords: Metal containing yarn, Breaking strength, Breaking elongation, Knitted fabric, 1x1 Rib

*Sorumlu yazar (Corresponding author): İlkan ÖZKAN, iozkan@cu.edu.tr 


\section{GíRiș}

Teknolojideki gelişmeler ve değişen insan ihtiyaçlar birçok yeni ürünün hayatımıza girmesinin yolunu açmıştır. Bu gelişmelere tekstil ürünleri de dahil olmuş endüstriyel uygulamalar, tıbbi tekstiller, askeri tekstiller ve ak1llı giysiler gibi birçok alanda kendisine yer bulmaya başlamıştır. İletken özelliğe sahip tekstil malzemeleri elektromanyetik kalkanlama, 1sitma, güç transferi, veri transferi, sensörler gibi birçok farklı ihtiyaca cevap vermektedir [1]. Metal kompozit tekstil yapıları ucuz olmaları kolay üretilebilmeleri, hafif ve esnek yapılı olmaları gibi avantajları sayesinde salt metallerin kullanıldığı elektromanyetik kalkanlama, iletkenlik vb. uygulamalarda da hizla kendisine yer bulmaktadır [2,3].

Patlama mukavemeti konvansiyonel örme kumaşlara uygulanan performans testlerinden biridir ve literatürde bulunan birçok çalışmada kullanılmıştır [4-6]. Bu test yönteminde deney numunesi pnömatik ya da hidrolik bir sistem vasitasıyla kontrollü olarak arttırılan bir basınca maruz bırakılır ve patladığı andaki basınç ve patlama yüksekliği üzerinden patlama mukavemeti değerlendirilir $[7,8]$.

$\mathrm{Bu}$ çalışmada, örme kumaşlar için literatürde yaygın olarak araştırılmış olan patlama mukavemeti özelliğinden farklı olarak, teknik amaçlarla kullanılabilecek metal içerikli örme kumaşların farklı doğrultudaki gerilmeler karşısındaki mukavemet ve uzama davranışları araştırılmıştır. Mukavemet ve uzama verileri metal içermeyen standart numuneler ile kıyaslanmış, elde edilen sonuçlar istatistiksel olarak analiz edilmiştir.

\section{2. ÖNCEKİ ÇALIŞMALAR}

Literatürde metal içerikli tekstil yapıları üzerine birçok araştırma bulunmakta olup bu araştırmalar örme kumaş [9-11], dokuma kumaş [12-16], dokusuz yüzey [17] ve son zamanlarda halılar olmak üzere [18-19] çok çeşitli tekstil yapılarını kapsamaktadır.
Önceki araştırmalarda tekstil malzemesine elektromanyetik kalkanlama, antibakteriyel aktivite, antifungal aktivite, antistatik özellik vb. özelliklerden bir ya da birkaçını kazandırmak temel amaç olarak karşımıza çıkmakta ve çalışmalar genellikle bu fonksiyonlara odaklanmaktadır. Bedeloğlu (2013) yaptığ çalışmada çelik tel içeren kompozit dokuma kumaş yapılarında bu fonksiyonlara ek olarak kullanım özelliklerini de incelemiştir. Sonuçlar çelik tel kullanımının kumaşa fonksiyonel özellikler kazandırdığını buna karşın eğilme dayanımını da arttırdığını ortaya koymuştur [20].

\section{MATERYAL VE METOT}

\section{1. İplik ve Kumaş Numunelerinin Üretimi}

Çalışmada, puntalama tekniği ile 3 bileşenli metal içerikli iplikler üretilmiştir. İplik yapısında kullanılan gümüş, bakır ve paslanmaz çelik metal tellerin basınçlı hava etkisiyle kırılmasının önlenmesi için bu teller işlem sırasında iki adet polyamid iplik arasında ortalanmıştır. Üretimler 5 bar basınç ve $150 \mathrm{~m} /$ dak üretim hızında gerçekleştirilmiştir. Filamentlere ait özellikler Çizelge 1'de verilmiştir.

Çizelge 1. Kullanılan ipliklere ait özellikler

\begin{tabular}{|l|l|}
\hline Filamet Türü & Özellikler \\
\hline Polyamid 6.6 (PA) & 78 denye/ 68 filament \\
\hline $\begin{array}{l}\text { Gümüş Monofilament } \\
(\mathrm{Ag})\end{array}$ & 107 denye $(\varnothing 47 \mu)$ \\
\hline Bakır Monofilament $(\mathrm{Cu})$ & 157 denye $(\varnothing 50 \mu)$ \\
\hline $\begin{array}{l}\text { Paslanmaz Çelik } \\
\text { Monofilament (SS) }\end{array}$ & 144 denye $(\varnothing 50 \mu)$ \\
\hline Metal İçerikli İplikler \\
\hline PA + SS + PA (PSSP) & 222 denier/ 137 \\
\hline PA + Ag + PA (PAgP) & 261 denier/ 137 \\
\hline PA + Cu + PA (PCuP) & 306 denier/ 137 \\
\hline
\end{tabular}

Paslanmaz çelik, bakır ve gümüş tel içerikli iplikler kullanılarak Shima Seiki SFF152 düz örgü makinesinde 1x1 Rib kumaşlar örülmüştür. Karşılaştırma amacıyla \%100 PA kontrol numunesi 
de üretilmiştir. Kumaşlara ait özellikler Çizelge 2'de verilmiştir.

Çizelge 2. Kumaş özellikleri

\begin{tabular}{|l|c|c|c|}
\hline Numune & İplik Türü & Çubuk/cm & Sira/cm \\
\hline Kontrol & PA & 12 & 14 \\
\hline $\mathrm{CuS}$ & PCuP & 12 & 11 \\
\hline $\mathrm{SS}$ & PSSP & 11 & 12 \\
\hline $\mathrm{AgS}$ & PAgP & 12 & 11 \\
\hline
\end{tabular}

\subsection{Mukavemet ve Uzama Testi}

Eksenel kuvvetler altında örme kumaşların mukavemet ve uzama özelliklerinin belirlenmesi için TS EN ISO 13934-1 (100 mm 100 mm-dak) standardı kullanılmıştır [21]. Testler Titan Universal test cihazı kullanılarak ilmek ve çubuk doğrultularında $\quad 5$ 'er tekrar şeklinde gerçekleştirilmiştir. Örme kumaşların esnek yapısından dolayı tam kopmanın sağlanabilmesi için kopma algılama hassasiyeti \%25 olarak seçilmiştir. Elde edilen sonuçlar istatistiksel olarak analiz edilmiştir.

\section{BULGULAR VE TARTIŞMA}

Rib örgü yapısına sahip kumaşlar sıra yönünde daha elastiktir. Metal içerikli kumaşların eksenel gerilmelere karşı davranışlarının bilinmesi, malzemenin kullanım alanına uygunluğunu belirleme açısından önemlidir. $\mathrm{Bu}$ amaçla, metal içerikli numunelere ve kontrol numunesine kopma mukavemeti ve uzama testi uygulanmış test sonuçlarına ait ortalama değerler Çizelge 3'de verilmiştir.

Çizelge 3. Kopma mukavemeti ve uzama sonuçları

\begin{tabular}{|l|c|c|}
\hline \multicolumn{3}{|c|}{ Mukavemet (N) } \\
\hline Numune Türü & Çubuk Yönü & Sıra Yönü \\
\hline Kontrol & 866,30 & 329,41 \\
\hline Bakır İçerikli & 867,09 & 350,21 \\
\hline P. Çelik İçerikli & 845,77 & 330,48 \\
\hline Gümüş İçerikli & 804,65 & 363,32 \\
\hline \multicolumn{3}{|c|}{ Uzama (\%) } \\
\hline Kontrol & 171,10 & 261,56 \\
\hline Bakı İçerikli & 119,09 & 300,09 \\
\hline P. Çelik İçerikli & 127,01 & 248,72 \\
\hline Gümüş İçerikli & 123,04 & 277,74 \\
\hline
\end{tabular}

İstatistiksel analizlerin ilk k1smında verilerin normal dağılıma uygunluğunu tespit etmek amaciyla Kolmogrov Simirnov testi uygulanmıştır. Yapılan analiz sonuçlar 0,05'den büyük anlamlılık değeriyle kopma mukavemeti ve uzaması verilerin normal dağılım gösterdiğini ortaya koymuştur.

Analizin ikinci kısmında gruplar arasında mukavemet ve uzama açısında anlamlı bir fark olup olmadığının tespiti için varyans analizi (ANOVA) testi yapılmıştır. Test sonuçları farklı kumaş grupları arasında kopma mukavemeti açısından çubuk $(p=0,324)$ ve sıra $(p=0,344)$ doğrultularında anlamlı bir fark olmadığını göstermiştir.

Test sırasında uygulanan gerilim karşısında ilk olarak düşük uzama kabiliyetine sahip metal filamentler kırılmakta ve testin devamında yükü metal içerikli ipliğin diğer birleşeni olan polyamid filmanentler taşımaktadır. Bu yüzden \%100 PA kontrol kumaşı ile metal içerikli kumaş numunelerinin mukavemetleri arasında anlamlı bir fark görülmemektedir.

Diğer taraftan metal filament kullanımı kumaşın sıra ve çubuk yönündeki yüzde uzama değerleri üzerinde anlamlı farklar meydana getirmiştir $(\mathrm{p}<0,05)$. Farkın hangi kumaş numuneleri arasında olduğunun tespiti amaciyla Tamhane çoklu karşılaştırma testi yapılmış olup sonuçlar Çizelge 4'de verilmiştir.

Çizelge 4. Çoklu karşılaștırma testi sonuçları

\begin{tabular}{|c|c|c|c|c|}
\hline $\begin{array}{l}\text { Bağımlı } \\
\text { Değisken }\end{array}$ & $\begin{array}{l}\text { Numune } \\
\text { Türü (I) }\end{array}$ & $\begin{array}{l}\text { Numune } \\
\text { Türü (J) }\end{array}$ & $\begin{array}{l}\text { Ort. Fark } \\
\text { (I-J) }\end{array}$ & Anlamlılik \\
\hline \multirow{5}{*}{$\begin{array}{l}\text { Çubuk } \\
\text { Yönü }\end{array}$} & \multirow{3}{*}{ Kontrol } & Bakır & $52,014^{*}$ & 0,001 \\
\hline & & P. Çelik & $44,096^{*}$ & 0,002 \\
\hline & & Gümüş & $48,060^{*}$ & 0,003 \\
\hline & \multirow{2}{*}{ Bakır } & P. Çelik & $-7,918$ & 0,331 \\
\hline & & Gümüş & $-3,954$ & 0,779 \\
\hline \multirow{5}{*}{$\begin{array}{l}\text { Sira } \\
\text { Yönü }\end{array}$} & \multirow{3}{*}{ Kontrol } & Bakır & $-38,528$ & 0,337 \\
\hline & & P. Çelik & 12,836 & 0,972 \\
\hline & & Gümüş & $-16,178$ & 0,955 \\
\hline & \multirow{2}{*}{ Bakır } & P. Çelik & $51,364^{*}$ & 0,014 \\
\hline & & Gümüș & 22,350 & 0,493 \\
\hline
\end{tabular}

* Ortalama fark 0,05 düzeyinde anlamlıdır.

Çizelge 4 incelendiğinde, kontrol numunesinin çubuk doğrultusundaki uzama değerinin metal içerikli kumaşlardan istatistiksel olarak anlamlı 
düzeyde daha yüksek olduğu görülmektedir. Bunun nedeni metal içerikli iplik yapısından bulunan metal tellerin çubuk doğrultusunda uzamayı sinırlandırmasıdır.

Sıra doğrultusundaki sonuçlar değerlendirildiğinde metal tel kullanımının bu doğrultudaki uzama özelliği üzerinde anlamlı bir fark yaratmadığı görülmektedir. Bunun nedeni rib örgü kumaşların bu doğrultuda daha esnek olmaları ve örgü yapısından gelen bu esneklikle belli bir uzunluk değerine kadar metal tellere yük binmemesidir. Testin devaminda metal teller polyamid filamentlerden önce kopmakta ve uzamanın geri kalanı kontrol kumaşında olduğu gibi polyamid filamentler tarafından sağlanmaktadır. Sonuç olarak sıra doğrultusunda benzer bir uzama davranışı görülmektedir. Metal içerikli numuneler kendi aralarında karşılaştırıldığında en düşük uzama değerini ise paslanmaz çelik içeren numune göstermiştir.

\section{SONUÇ}

Yapılan çalışma kapsamında gümüş bakır ve çelik tel içeren ipliklerden üretilmiş rib örgü kumaşların eksenel gerilmeler karşısında gösterdiği mukavemet ve uzama davranışları istatistiksel olarak değerlendirilmiştir. Elde edilen sonuçlar maddeler halinde aşağıda özetlenmiştir.

- Kumaş yapısında metal tel kullanımının çubuk ve sıra doğrultularında kopma mukavemeti açısından anlamlı bir fark yaratmadığı tespit edilmiştir.

- Uygulanan gerilim karşısında ilk olarak düşük uzama kabiliyetine sahip metal filamentler kırılmakta olduğu ve testin devamında yükü metal içerikli ipliğin diğer birleşeni olan polyamid filamentlerin taşıdığı gözlenmiştir. $\mathrm{Bu}$ yüzden \%100 PA kontrol kumaşı ile metal içerikli kumaş numunelerinin mukavemetleri arasında anlamlı bir fark ortaya çıkmamıştır.

- Metal filament kullanımı kumaşın sıra ve çubuk yönündeki yüzde uzama değerleri üzerinde anlamlı farklar meydana getirmiştir.

- İplik yapısında bulunan metal tellerin çubuk doğrultusunda uzamayı sınırlandırmasının etkisiyle kontrol numunesinin çubuk doğrultusundaki uzama değerinin metal içerikli kumaşlardan istatistiksel olarak anlamlı düzeyde daha yüksek çıkmıştır.

- Rib örgü kumaşların bu doğrultuda daha esnek olmaları ve örgü yapısından gelen bu esneklikle belli bir uzunluk değerine kadar metal tellere yük binmediği için sıra doğrultusundaki kopma uzaması değerleri arasında anlamlı bir fark görülmemiştir.

- Metal içerikli kumaşlar için tespit edilen kopma ve uzama değerleri, bu kumaşların teknik amaçlarla kullanılması durumunda karşılaştıkları eksenel yükler karşında işlevlerini yerine getirebilecekleri sınırları ortaya koyması bakımından önemlidir.

\section{KAYNAKLAR}

1. Bedeloğlu, A., Sünter, N., Bozkurt, Y., 2010. Elektriksel Olarak İletken Tekstil Yapıları, Üretim Yöntemleri ve Kullanım Alanları, Tekstil ve Mühendis, 17, 7-17.

2. Roh, J.S., Chi, Y.S., Kang, T.J., Nam, S. W., 2008. Electromagnetic Shielding Effectiveness of Multifunctional Metal Composite Fabrics, Textile Research Journal, 78(9), 825-835.

3. Brzeziński, S., Rybicki, T., Karbownik, I., Malinowska, G., Śledzińska, K., 2012. Textile Materials for Electromagnetic Field Shielding Made With the Use of Nano-and Microtechnology, Open Physics, 10(5), 1190-1196.

4. Mezarciöz, S., Oğulata, R.T., 2010. Süprem Kumaşlarda Patlama Mukavemeti Değerinin Taguchi Ortogonal Dizayna Göre Optimizasyonu, Tekstil ve Konfeksiyon, 20(4), 320-328.

5. Demiryürek, O., Uysaltürk, D., 2016. Viloft/Polyester Karışımlı Örme Kumaşların Patlama Mukavemeti ve Boncuklanma Özelliklerinin Araştırılması, Tekstil ve Mühendis, 23(102), 105-111.

6. Akaydın, M., Yahya, C.A.N., Önder, Ö.R.E.N., Özerdoğan, M.A., 2009. Ring Penye ve Kompakt İpliklerden Örülen Temel Atkılı Örme Kumaşların Patlama mukavemetleri Üzerine Bir Araştırma, Tekstil ve Mühendis, 16(74), 17-20. 
7. TS 393 EN ISO 13938-1, 1999. Patlama Mukavemetinin ve Patlama Gerilmesinin Tayini için Hidrolik Metot.

8. TS 393 EN ISO 13938-2, 1999. Patlama Mukavemetinin ve Patlama Gerilmesinin Tayini için Pnömatik Metot.

9. Ortlek, H.G., Gunesoglu, C., Okyay, G., Turkoglu, Y., 2012. Investigation of Electromagnetic Shielding and Comfort Properties of Single Jersey Fabrics Knitted from Hybrid Yarns Containing Metal Wire, Tekstil ve Konfeksiyon, 22(2), 90-101.

10. Ceken, F., Kayacan, Ö., Özkurt, A., Uğurlu, Ş. S., 2012. The Electromagnetic Shielding Properties of Some Conductive Knitted Fabrics Produced on Single or Double Needle Bed of a Flat Knitting Machine, Journal of The Textile Institute, 103(9), 968-979.

11. Su, C., Chern, J., 2004. Effect of Stainless Steelcontaining Fabrics on Electromagnetic Shielding Effectiveness, Textile Research Journal, 74(1), 51-54.

12. Cheng, K.B., Cheng, Ta-Wui, Nadaraj, R.N., Giri Dev, V.R., Ramalingam, N., 2006. Electromagnetic Shielding Effectiveness of the Twill Copper Woven Fabrics, Journal of Reinforced Plastics and Composites, 25(7), 699-709.

13. Ortlek, H.G., Saracoglu, Ö.G., Saritas, Ö., Bilgin, S., 2012. Electromagnetic Shielding Characteristics of Woven Fabrics Made of Hybrid Yarns Containing Metal Wire, Fibers and Polymers, 13(1), 63-67.

14. Rajendrakumar, K., Thilagavathi, G., 2012. Electromagnetic Shielding Effectiveness of Copper/PET Composite Yarn Fabrics, Indian Journal of Fiber and Textile Research, 37(2), 133-137.

15. Duran, D., Kadoğlu, H., 2012. A Research on Electromagnetic Shielding With Copper Core Yarns. Tekstil ve Konfeksiyon, 22(4), 354-359.

16. Duran, D., Kadoğlu, H., 2015. Electromagnetic Shielding Characterization of Conductive Woven Fabrics Produced With Silvercontaining Yarns, Textile Research Journal, 85(10), 1009-1021.

17. Ozen, M.S., Sancak, E., Soin, N., Shah, T.H., Siores, E., 2016. Investigation of Electromagnetic Shielding Effectiveness of
Needle Punched Nonwoven Fabric Produced from Conductive Silver Coated Staple Polyamide Fibre, The Journal of The Textile Institute, 107(7), 912-922.

18. Özkan, İ., Duru Baykal, P., Karaaslan, M., 2019. Investigation of Electromagnetic Shielding Properties of Metal Composite Tufted Carpet. The Journal of The Textile Institute, Doi: 10.1080/00405000.2019. 1643213

19. Özkan, İ., Duru Baykal, P., Gülnaz, O., 2019. Investigation of Antibacterial and Antifungal Properties of Tufting Carpets Containing Metal Composite Yarns, The Journal of The Textile Institute, 110(5), 756-763.

20. Bedeloglu, A., 2013. Investigation of Electrical, Electromagnetic Shielding, and Usage Properties of Woven Fabrics Made from Different Hybrid Yarns Containing Stainless Steel Wires, The Journal of The Textile Institute, 104(12), 1359-1373.

21. TS EN ISO 13934-1, 2013. Tekstil- Kumaşların Gerilme Özellikleri-Bölüm 1: En Büyük Kuvvetin ve En Büyük Kuvvet Altında Boyca Uzamanın Tayini-Şerit Metodu. 
